\title{
The influence of exposure duration and context length on word recall: A replication of Tulving et al. (1964)
}

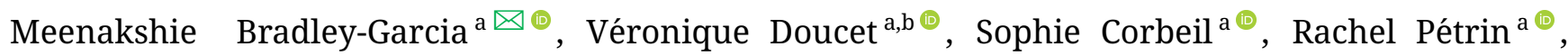

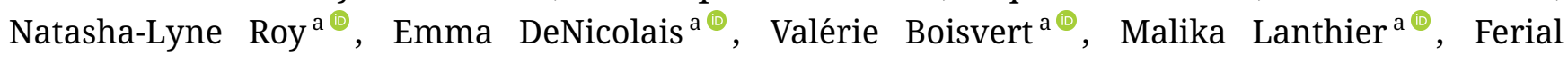

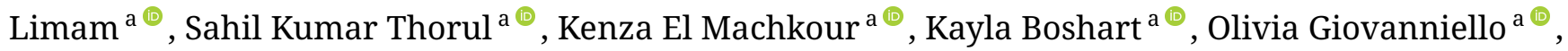

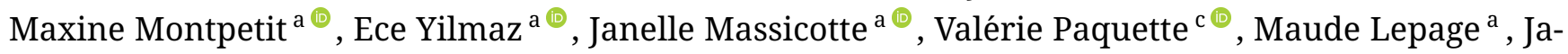

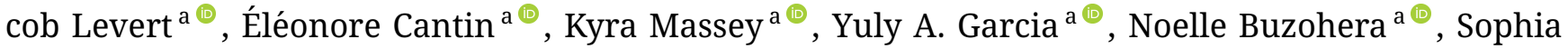

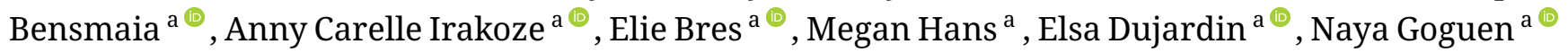
\& Melanie J. Sekeres ${ }^{\text {a }}$ (๑)

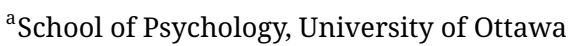

${ }^{\mathrm{b}}$ Department of Criminology, University of Ottawa

${ }^{\mathrm{c}}$ Department of Linguistics, University of Ottawa
\end{abstract}

\begin{abstract}
Tulving and colleagues (1964) pioneered the study of word recognition by investigating the influence of exposure duration and context length on accurate word identification. The present experiment aimed to replicate the original methodology with modern technology and a demographically heterogeneous sample. Male and female participants $(n=58)$ between 18-69 years with varying levels of education and who identified English or French as their dominant language were randomly assigned to a context length condition containing either $0,2,4$, or 8 words from specific sentences. Participants were shown 18 target words for $16.67 \mathrm{~ms}$ and asked to type the target word after each one was presented. Participants were then instructed to type each target word in a corresponding fragmented sentence which varied in length according to the number of context words presented (0-, 2-, 4-, or 8-word context). The procedure was repeated for 6 subsequent exposure durations (33.33, 50.00, 66.67, 83.33, 100.00, and $116.67 \mathrm{~ms}$ ). Repeated Measures ANOVA indicated a significant effect of exposure duration and context length on accurate recall $(\mathrm{p}<$ .002). These results corroborate those found by Tulving et al. (1964). No significant interaction was observed between these two variables on recall accuracy $(p>.05)$ compared to what was demonstrated by Tulving et al. (1964). This suggests that the robust memory enhancing effects of longer exposure durations during encoding and longer context lengths during retrieval are reliably observed across a diverse participant sample. To improve generalizability, follow-up studies should use a larger participant sample to determine how demographic factors, including age, sex, education, and language, may influence the effects of exposure duration and context length on word recognition in recall tasks.
\end{abstract}

Keywords $₫$ replication, recall, context length, exposure duration, visual memory.

\section{mbrad048@uottawa.ca}

\subsection{2/tqmp.17.2.r001}

\section{Introduction}

Early research investigating word recognition used tachistoscopic training to assess recognition of briefly displayed visual stimuli (Manelis, 1977; Tulving \& Gold, 1963; Tul-
Acting Editor $\square$ Denis Cousineau (Université d'Ottawa)

\section{Reviewers}

- No authors from the original study reviewed this replication. 
al., 1964), semantic properties (Batel, 2019), and exposure duration (Ballardini, Yamashita, \& Wallace, 2008; Goldstein, McAfee, \& Suri, 2011; Pfafflin, 1974; Tulving et al., 1964; von Hippel \& Hawkins, 1994). The representation of a visual stimulus lasts approximately $100 \mathrm{~ms}$ in the iconic memory before being transferred to the working memory via attentional processes (Bradley \& Pearson, 2012). The information may also be transferred to long-term memory through rehearsal strategies (Cowan, 2008). The activation threshold of sensory memory has been found to be proportional to the frequency of a word's occurrence, with familiar words having a lower activation threshold and requiring fewer cognitive resources to be properly encoded (Colombo, Pasini, \& Balota, 2006). However, brief exposure to a stimulus limits the ability to create a visual feedback loop. Therefore, longer exposure to visual stimuli aids with encoding and retrieval (Sperling, 1963). Remembering a word can also be influenced by the contextual information that precedes visual stimuli (Lee, Liu, \& Tsai, 2012), as contextual information serves as retrieval cues (Frankland, Josselyn, \& Köhler, 2019). Accordingly, longer sequences of words, which contain higher amounts of contextual information, as opposed to shorter sequences, facilitate the encoding of words and heighten retrieval accuracy (Celata, 2020).

Tulving and colleagues were pioneers in the field of cognitive psychology due to their research on word recognition. In 1964, Tulving et al. examined the influence of exposure duration and context length on accurate word recognition using a tachistoscope within a sample of one hundred female undergraduate students. They demonstrated that these two sources independently facilitate response accuracy but also that they interact together to further enhance accurate recall. To our knowledge, no study has replicated this experiment with a more representative sample of participants with varying demographic characteristics including a wide range of ages (Allen, Madden, Weber, \& Groth, 1993), first languages (Brysbaert, Lagrou, \& Stevens, 2017), levels of education (Lachman, Agrigoraei, Murphy, \& Tun, 2010), and sex (Andreano \& Cahill, 2009).

The present study aimed to replicate the methodology of Tulving et al. (1964) with modern technology and a heterogeneous sample to determine if the findings could be generalized. Based on the results of Tulving et al. (1964), we predict that an increase in both exposure duration (16.67, 33.33, 50.00, 66.67, 83.33, 100.00, $116.67 \mathrm{~ms}$ ) of visually presented words and available contextual information in fragmented sentences $(0,2,4$, or 8 words) will progressively facilitate the recall of words in female and male participants ranging from 18 to 69 years and from various linguistic (French or English) and educational (high school, college, bachelor, or graduate studies) backgrounds.

\section{Methods}

The present study adopted the methodology of Tulving et al. (1964), with the exception that the visual stimuli were shown and the responses were recorded using Qualtrics, a computerized data collection program, as a substitute for the original tachistoscope and the manual recording of responses. Several methodological details were not originally specified, including the exposure duration of the fixation letters, the practice words used, or the time allotted to complete the sentences. These were identified in this replication. Tulving et al. (1964) employed the term recognition interchangeably with recall, to represent the tasks participants completed. This replication refers to this process as "recall" tasks, as they are now considered a distinct process from recognition. Recall involves the retrieval of items from memory, while recognition involves a judgment on the familiarity of items (Eichenbaum, Yonelinas, \& Ranganath, 2007; Sadeh, Ozubko, Winocur, \& Moscovitch, 2014, 2016). The stimuli and the raw data for this experiment have been made available online (https://osf.io/ yxz9s/).

\section{Recruitment}

Undergraduate students enrolled in a cognitive psychology course at the University of Ottawa during the fall of 2020 collaborated on this project for course credit. Each student invited their friends and family members to participate in this experiment by sending them a standard e-mail that included a description of the study and the Qualtrics electronic link to access the experiment. Participants were asked to complete the task within seven days of receiving the link and during a time in which they would be free of distractions for 30 minutes.

\section{Participants}

Data was obtained from 141 participants. Participants would have been excluded if they had a history of epilepsy $(n=0)$, due to the rapid nature of the presentation of visual stimuli, or if they were below the age of 18 years $(n=0)$. Exclusions were applied for participants who did not complete the task ( $n=71$ ), made multiple attempts ( $n=8$ ), or failed to complete more than $80 \%$ of the trials $(n=4)$. Following exclusions, data were obtained from 58 participants (female, $n=39$; male, $n=19$ ) between 18 and 69 years $(M=29.2, S D=13.7)$ from various levels of education (high school, college, bachelor, Masters, or Ph.D.) and whose first and dominant language was either French or English (Table 1). Participants were randomly assigned to one of four context length conditions with either 0 words ( $n=15$ ), 2 words ( $n=12$ ), 4 words ( $n=18$ ), or 8 words ( $n=13$ ) of 18 specific sentences. 
Figure 1 - The word-like smudge. The word-like smudge "banana” was presented 18 times at $16.67 \mathrm{~ms}$ to represent an exposure duration of $0 \mathrm{~ms}$. The data for the word-like smudge task was not recorded.

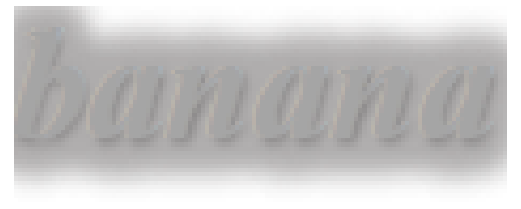

\section{Stimuli}

The stimuli used in this replication consisted of 18 target words which were the last words of 18 sentences (Table 2). The 18 sentences were shown to all participants but varied in length according to the number of context words presented. For the four conditions, either all 8 words ( 0 word context), the first 6 words (2-word context), the first 4 words (4-word context), or only the target words (8-word context) were omitted from each sentence. For instance, to recall the first target word (alliance), the sentence presented was either: "a military __" (2-word context), "Nations form a military __" (4-word context), or "Countries in the United Nations form a military __" (8-word context), whereas the 0 -word condition was presented as follows: “_”. The word-like smudge appeared in the centre of the screen 18 times for $16.67 \mathrm{~ms}$ and aimed to represent a duration of $0 \mathrm{~ms}$ (Figure 1). The target words, practice words, and fixation letters were presented centrally in black capitalized letters on a white background on the screen. The fixation letters "XLOXLOXL" were similarly presented for $33.33 \mathrm{~ms}$ between every practice and target word. These aimed to focus the participants' attention to the centre of the screen as this is where the target words would later appear.

\section{Materials}

Participants were asked to use their personal LCD monitors to complete the experiment. LCD monitors have a refresh rate of 60 hertz, and therefore, have a refresh cycle of 16.67 ms per second (Bognár, Csibri, András, \& Sáry, 2016). The $20 \mathrm{~ms}$ increments from the original study were adapted to increments of $16.67 \mathrm{~ms}$ for the current study. This experiment was administered remotely via Qualtrics to maintain safety regulations from COVID-19. The internet browser entered full-screen mode, when accessed, to minimize potential distractions.

\section{Procedure}

The procedure was identical for all participants, except for the number of words provided in each sentence which var- ied according to their assigned context length condition. The experiment began with a welcome message, a consent form, and then a short demographic questionnaire. The experiment continued with a practice block of 6 words, each shown for either $16.67,33.33,50.00,66.67,83.33$, or 100.00 ms. Participants were asked to type the word shown on the screen immediately after each one was presented. Next, the word-like smudge was displayed 18 times for $16.67 \mathrm{~ms}$ to represent an exposure duration of $0 \mathrm{~ms}$. Then, the 18 target words were individually presented for $16.67 \mathrm{~ms}$ and participants were asked to type the target word instantly after each one was presented. After all target words were shown, participants were presented with fragmented sentences, which varied according to their context length condition (0-, 2-, 4-, 8-word), and were instructed to remember and type each target word to complete the corresponding 18 sentences. This protocol was repeated for subsequent exposure durations of 33.33, 50.00, 66.67, 83.33, 100.00, and $116.67 \mathrm{~ms}$, wherein the target words were presented in the same fixed order across each trial (Figure 2).

\section{Coding}

Recall of target words during the sentence completion task was scored as follows: a score of 0 was assigned to an incorrect response, a score of 0.5 was assigned when at least $50 \%$ of the target word was recalled and typed correctly (i.e. domino/dominos, musical/music, murder, approve, festive, locate, residence), and a score of 1 was assigned when at least $90 \%$ of the target word was recalled and spelled correctly, such that minor errors were not penalized. The target words could be recalled in any order using free recall for the first group of participants ( 0 -word context) but had to be recalled in a fixed order according to the sentence using cued recall for the other groups (2-, 4-, 8-word context). For each participant, the mean of accurate word recall scores was calculated by dividing the sum of the coded data for each exposure duration by the 7 exposure durations. No data was recorded when participants typed the briefly presented target words immediately after they were presented or during the word-like smudge task. 
Figure 2 - Flowchart of the experimental protocol for this replication study of Tulving, Mandler, and Baumal (1964). The 6 practice words presented were accident (16.67 ms), candlelight (33.33 ms), leopard (50.00 ms), eucalyptus (66.67 ms), table $(83.33 \mathrm{~ms})$, and pianist $(100.00 \mathrm{~ms})$. The fixation letters "XLOXLOXL" were presented before and after each practice word, word-like smudge, and target word for $33.33 \mathrm{~ms}$. To illustrate the experimental protocol, the word "ALLIANCE” is representative of the target words used in the experiment.

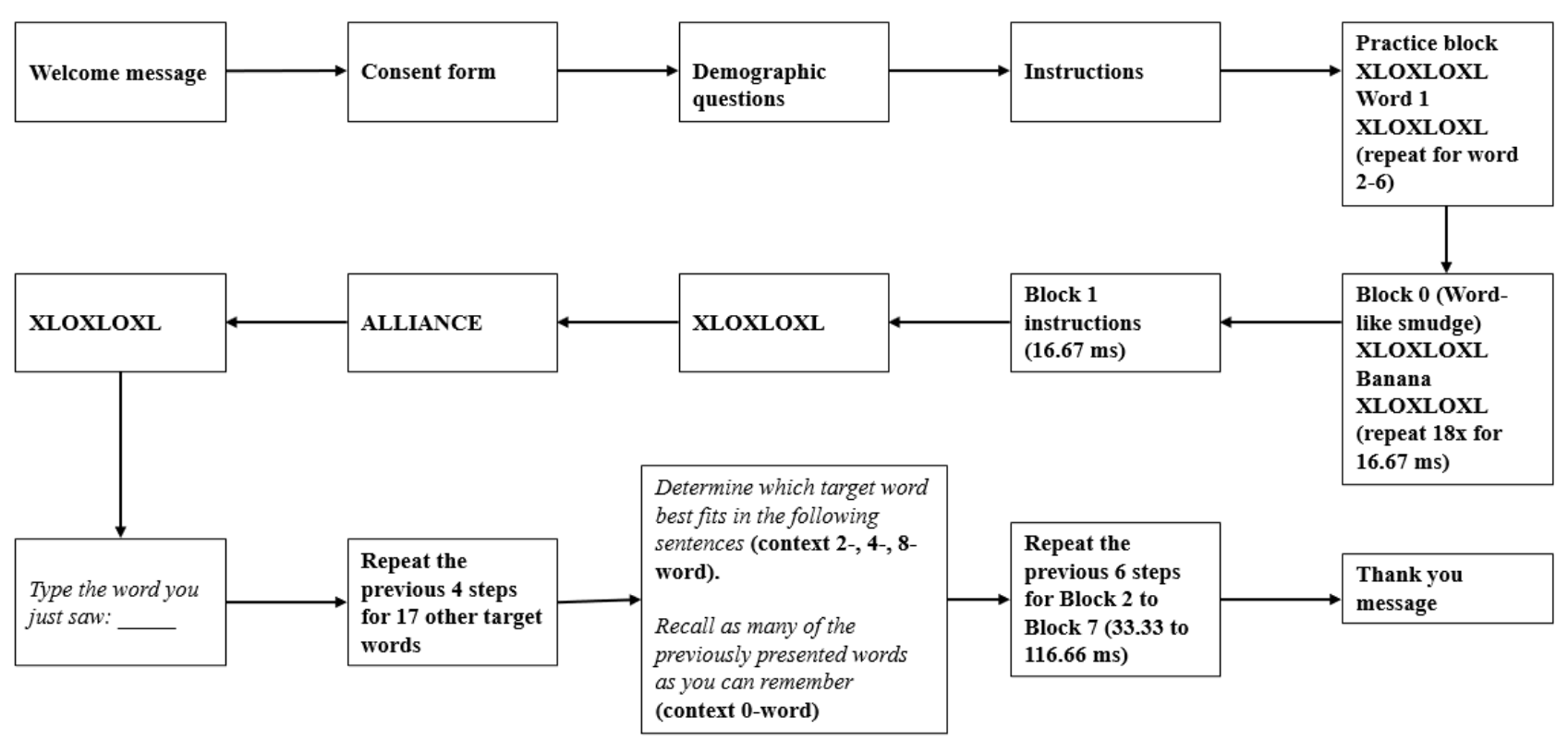

\section{Statistical Analysis}

Statistical analyses were performed using SPSS 27 (RRID:SCR_002865). A Repeated Measures Analysis of Variance (RMANOVA) was conducted with all male and female participants ( $n=58$ ) between 18 and 69 years, from various levels of education (high school, college, bachelor's, master's, and doctorate degrees), and whose dominant language is French or English. This analysis included a within-subject design to measure the effect of exposure duration as well as a between-subject design to measure the effect of context length and their interaction on word recall accuracy. A 95\% confidence interval was used with an alpha level set to $p<.05$. A Greenhouse-Geisser correction $(\varepsilon=.57$ ) was implemented as the assumption for Mauchly's Sphericity test was violated $\left[\chi^{2}(20)=135.99\right.$, $p=.07]$. As the equality of variance was not assumed, a post-hoc pairwise comparison test with Dunnett's T3 correction enabled comparison of the four levels of context length on accurate word recall.

\section{Results}

A RMANOVA was performed using the within-subject factor exposure duration $(16.67,33.33,50.00,66.67,83.33$,
$100.00,116.67 \mathrm{~ms}$ ) and between-subject factor context length (0-, 2-, 4-, 8-word sentences) to compare the main effects of exposure duration and context length and their interaction on word recall accuracy. The factorial analysis revealed a statistically significant main effect of exposure duration on accurate recall $[F(3.43,185.5)=104.34$, $p<.001$, partial $\eta^{2}=.66$ ]. Exposure duration accounted for $66 \%$ of the variability in word recall scores. Pairwise comparison test showed a significant difference between each exposure duration $(p<.01$ ), except between 83.33 and $100.00 \mathrm{~ms}(p=.494)$. As shown in Figure 3, recall accuracy was enhanced when target words were displayed for $116.67 \mathrm{~ms}$ compared to $16.67 \mathrm{~ms}$. These findings corroborate those of Tulving et al. (1964) and suggest that accurate retrieval is facilitated by longer exposure time to a visual stimulus.

The RMANOVA also identified a significant main effect of context length on recall accuracy, with a very small effect size $\left[F(3,54)=5.57, p=.002\right.$,partial $\left.\eta^{2}=.23\right]$. This indicates that $23 \%$ of the variance in recall scores was explained by context length. Post-hoc analyses only showed a significant difference in recall accuracy between context 0 - and 8-word ( $p=.018$ ) and context 2- and 8-word $(p=.01)$. As shown in Figure 3, participants with no con- 
Figure 3 - Scores for accurate recall among participants in each context length condition during the various trials of exposure duration. Mean of recall accuracy for the participants $(n=58)$ in the four independent levels of context length $(0$, 2 , 4, and 8 words) for the seven repeated levels of exposure duration (16.67, 33.33, 50.00, 66.67, 83.33, 100.00, and 116.67 ms). Error bars represent correlation-adjusted and difference-adjusted 95\% confidence intervals (Cousineau, 2017; Efron \& Tibshirani, 1993). The data from the context conditions have been slightly shifted to the right to avoid overlap.

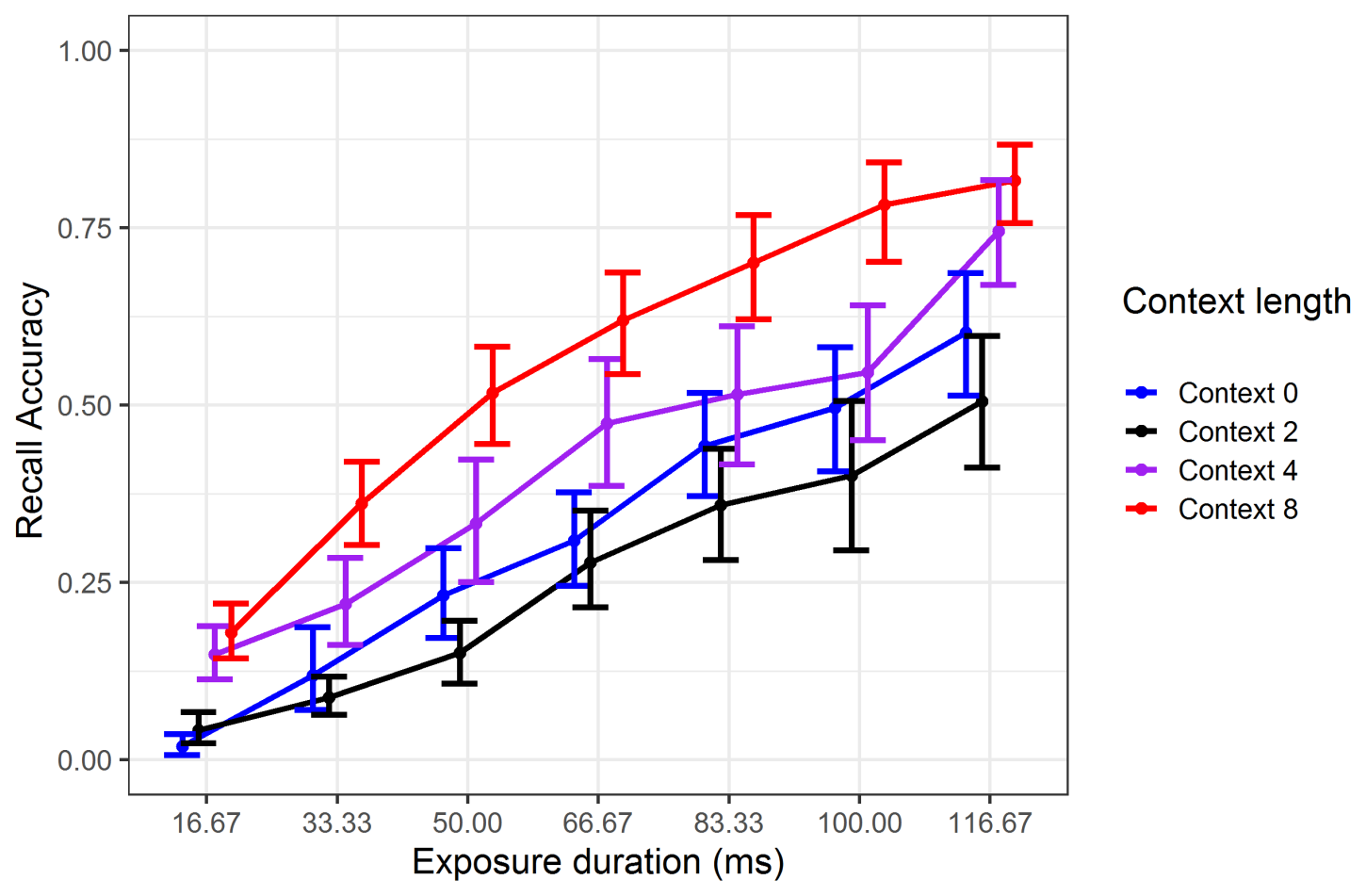

text words (0-word) had lower recall accuracy than those who were provided with 4 words and those with 8-word sentences but had higher recall than those with 2-word sentences. Participants with no context provided (0 words) were able to recall words in no fixed order, which may have decreased the level of difficulty of this task, resulting in better accuracy compared to the 2-word context condition group. The very limited contextual information provided by the 2-word context condition likely was not sufficient to cue recall, as words needed to be remembered in the original presentation order, thereby increasing the cognitive effort required for accurate recall (Morton, 1969). In comparison, participants with 4-word and 8-word sentences were provided with additional relevant cues, which aided in accurately recalling the target word. In contrast to the present findings, Tulving et al. (1964) found that participants with no contextual information had the lowest recall scores compared to those with 2-, 4-, and 8-word sentences. Therefore, the present findings partially corroborate those found by Tulving and colleagues (1964). These results propose that sufficient relevant contextual information, designated by the number of words presented in fragmented sentences, aid in recalling briefly presented words.

The present study did not find a significant interaction between context length and exposure duration on recall accuracy $\left[F(10.3,185.5)=1.02, p=.43\right.$, partial $\eta^{2}=$ $.05]$. The interaction between these two variables only accounted for a small variability of $5 \%$ in the recall accuracy scores. In contrast, Tulving et al. (1964) noted a combined effect of these two variables. They reported that participants with 2-word sentences had increased recall accuracy compared to those with 4 words as time increased above $100 \mathrm{~ms}$ and to those with no context across all exposure durations. However, participants with 2-word sentences had lower recall accuracy than those with 8-word sentences across all exposure durations. The present findings suggest that the briefest exposure to the target word combined with limited contextual cues likely increased the difficulty of retrieval, as demonstrated by the scores of participants with 2-word sentences. 
Exploratory analyses were performed to assess potential mediating effects of demographic factors, such as first language, sex, age group, and level of education, on the influence of exposure duration and context length on recall accuracy. However, splitting participants according to these demographic variables resulted in a low number of participants distributed between the context length conditions, therefore prohibiting some analyses. Consequently, only the exploratory analyses for sex (female or male) and first language (English or French) were provided in the supplemental data (https://osf.io/yxz9s/).

\section{Discussion}

The objective of the current study was to replicate the experiment of Tulving et al. (1964) to determine if their results could be generalized by using a more heterogeneous participant sample. Unlike the original sample, which included only female participants between the ages of 18 and 40 years, the present study's sample included male and female participants from a wider age range and from different linguistic and educational backgrounds. Additionally, the present study demonstrated the feasibility of methodological adaptations using modern technological tools. The incorporation of LCD monitors and Qualtrics software, rather than a tachistoscope, heightens the efficiency, the reliability, and the consistency of the presentation of words in the task (Greene, 2016).

The present study found that accurate recall of visual stimuli is enhanced by prolonged exposure of target words during initial encoding and by the availability of contextual cues at the time of retrieval. By using a more diverse sample of male and female participants between the age of 18 and 69 years from various educational (high school, college, bachelor's, master's, or doctorate degrees) and linguistic (French or English) backgrounds, this study extends the generalizability of Tulving et al. (1964) findings in a sample that is more representative of a broader population.

Specifically, the present study found that longer exposure durations to the target word during encoding independently facilitated accurate word recall during the sentence completion task, corroborating the conclusions of Tulving et al. (1964). Although visual information is perceived by the iconic memory within several milliseconds (Bradley \& Pearson, 2012), a longer exposure duration to a word facilitates encoding by creating a visual feedback loop (Sperling, 1963). According to von Hippel and Hawkins (1994), increased exposure duration can significantly facilitate completion of fragmented sentences. Ballardini et al. (2008) and Pfafflin (1974) demonstrated that, as the exposure to a word increases, the number of errors involved in recall decreases. Therefore, the rate of recall increases as a function of exposure duration (Goldstein et al., 2011).

The present study also demonstrated that additional contextual information provided during the sentence completion task enhances retrieval accuracy, confirming the main effect found by Tulving et al. (1964). Similarly, Celata (2020) found that longer sequences of words enhance the accurate encoding of words, likely by serving as retrieval cues (Frankland et al., 2019; Lee et al., 2012).

An interaction between exposure duration at the encoding phase and word context length at the retrieval phase was originally reported by Tulving et al. (1964). As this interaction was not presently confirmed, it is important to consider potential factors that might contribute to this incongruity. First, the smaller sample size of the present study ( $n=58$ ) compared to the sample of Tulving et al. (1964) ( $n=100)$ may have limited the power of our analyses. Additionally, Tulving et al. (1964) did not provide the effect sizes or confidence intervals of their findings, thereby not permitting a rigorous comparison of the variability among the groups (Nuzzo, 2014).

This study aimed to replicate the methodology of Tulving et al. (1964), therefore the target words were presented in a fixed order during the encoding trial to match the original methods. Fixed order presentation often creates a serial order carryover effect, as the presentation of the words during one experimental trial facilitates the encoding of the words in the subsequent trials. This is particularly problematic to the internal validity of repeated measures design (Brooks, 2012). Randomization of the presentation of both the 18 target words and the 18 sentences could control for the potential confounding serial order carryover effects observed when using fixed order presentation. This will also minimize the predictive power of the target words and sentences, thereby reducing the participants' ability to predict the following word in the sequence. Also, participants in the original study may have had continuous access to the sentences in their notebook, whereas sentences were only presented at the end of each trial in this study. Future studies should seek to compare the potential memory enhancing effects of continuous, relative to intermittent, exposure to contextual cues at the time of retrieval.

Qualtrics did not permit the configuration of a time limit for participants to complete the recall tasks. This limited the ability to control the potential effects of memorization techniques, distractions, or time delays during both the encoding and recall tasks (Kazerounian \& Grossberg, 2014). The use of a response time-limit during these tasks would provide better control for these potential confounding effects on recall accuracy, making it easier to standardize testing conditions across participants. Therefore, we recommend using the software Gorilla, as it enables the 
configuration of a time interval for participants to respond to the various tasks. Furthermore, future studies should consider recording participants virtually during the experiment to mitigate potential distractions.

Finally, to heighten the statistical power of these analyses in a diverse sample, it would be important to both increase the sample size of participants with specific demographic factors, such as age, sex, first language, and level of education, and ensure an equal distribution of participants across demographic conditions. This would permit the assessment of the potential influence of these factors in mediating the effects of exposure duration and context length on word recall.

\section{Authors' note}

Various authors contributed as part of an undergraduate course project while others continued to volunteer for the preparation of this manuscript. The raw data obtained from Qualtrics, the stimuli used for this experiment, and the exploratory analysis have been made available [https: //osf.io/yxz9s/].

\section{References}

Allen, P. A., Madden, D. J., Weber, T. A., \& Groth, K. E. (1993). Influence of age and processing stage on visual word recognition. Psychology and aging, 8(2), 274282. doi:10.1037//0882-7974.8.2.274

Andreano, J. M., \& Cahill, L. (2009). Sex influences on the neurobiology of learning and memory. Learning \& memory, 16(4), 248-266. doi:10.1101/lm.918309

Ballardini, N., Yamashita, J. A., \& Wallace, W. P. (2008). Presentation duration and false recall for semantic and phonological associates. Consciousness and Cognition, 17(1), 64-71. doi:10.1016/j.concog.2007.01.008

Batel, E. (2019). Context effect on 12 word recognition: Visual versus auditory modalities. Journal of Psycholinguistic Research, 49(3), 233-245. doi:10.1007/s10936019-09683-6

Bognár, A., Csibri, P., András, C. M., \& Sáry, G. (2016). Lcd monitors as an alternative for precision demanding visual psychophysical experiments. Perception, 45, 1070-1083. doi:10.1177/0301006616651954

Bradley, C., \& Pearson, J. (2012). The sensory components of high-capacity iconic memory and visual working memory. Frontiers in psychology, 3, 355-359. doi:10. 3389/fpsyg.2012.00355

Brooks, J. L. (2012). Counterbalancing for serial order carryover effects in experimental condition orders. Psychological Methods, 17(4), 600-614. doi:: 10 . 1037 / a0029310

Brysbaert, M., Lagrou, E., \& Stevens, M. (2017). Visual word recognition in a second language: A test of the lexical entrenchment hypothesis with lexical decision times. Bilingualism: Language and Cognition, 20(3), 530-548. doi:10.1017/S1366728916000353

Celata, C. (2020). Bottom-up probabilistic information in visual word recognition: Interactions with phonological and morphological functions. Language Sciences, 78, 1-9. doi:10.1016/j.langsci.2019.101267

Chen, Z., \& Cowan, N. (2005). Chunk limits and length limits in immediate recall: A reconciliation. Journal of EXperimental Psychology: Learning, Memory, and Cognition, 31(6), 1235-1249. doi:10.1037/0278-7393.31.6. 1235

Colombo, L., Pasini, M., \& Balota, D. A. (2006). Dissociating the influence of familiarity and meaningfulness from word frequency in naming and lexical decision performance. Memory \& cognition, 34(6), 1312-1324. doi:10.3758/bf03193274

Cousineau, D. (2017). Varieties of confidence intervals. Advances in Cognitive Psychology, 13(2), 140-155. doi:10. 5709/acp-0214-z

Cowan, N. (2008). Chapter 20 what are the differences between long-term, short-term, and working memory? Progress in Brain Research, 169, 323-338. doi:10.1016/ s0079-6123(07)00020-9

Efron, B., \& Tibshirani, R. J. (1993). An introduction to the bootstrap. doi:10.1007/978-1-4899-4541-9

Eichenbaum, H., Yonelinas, A. P., \& Ranganath, C. (2007). The medial temporal lobe and recognition memory. Annual Review of Neuroscience, 30, 123-152. doi:10 . 1146/annurev.neuro.30.051606.094328

Frankland, P. W., Josselyn, S. A., \& Köhler, S. (2019). The neurobiological foundation of memory retrieval. $\mathrm{Na}$ ture Neuroscience, 22(10), 1576-1585. doi:10 . 1038 / s41593-019-0493-1

Goldstein, D. G., McAfee, R. P., \& Suri, S. (2011). The effects of exposure time on memory of display advertisements. In M. Mouse (Ed.), Proceedings of the 12th acm conference on electronic commerce - ec '11 (pp. 19). doi:10.1145/1993574.1993584

Greene, E. (2016). Recognizing words and reading sentences with microsecond flash displays. PloS One, 11(1), e0145697-e0145699. doi:10.1371/journal.pone. 0145697

Kazerounian, S., \& Grossberg, S. (2014). Real-time learning of predictive recognition categories that chunk sequences of items stored in working memory. Frontiers in Psychology, 5(1053), 1-9. doi:10.3389/fpsyg. 2014. 01053

Lachman, M. E., Agrigoraei, S., Murphy, C., \& Tun, P. A. (2010). Frequent cognitive activity compensates for education differences in episodic memory. The Ameri- 
can Journal of Geriatric Psychiatry, 18(1), 4-10. doi:10. 1097/JGP.0b013e3181ab8b62

Lee, C. Y., Liu, Y. N., \& Tsai, J. L. (2012). The time course of contextual effects on visual word recognition. Frontiers in psychology, 3, 285-289. doi:10 . 3389/ fpsyg . 2012.00285

Manelis, L. (1977). Frequency and meaningfulness in tachistoscopic word perception. The American Journal of Psychology, 90(2), 269-280. doi:10.2307/1422049

Morton, J. (1969). Interaction of information in word recognition. Psychological Review, 76(2), 165-178. doi:10 . 1037/h0027366

Nuzzo, R. (2014). Statistical errors: P values, the "gold standard" of statistical validity, are not as reliable as many scientists assume. Nature, 506(7487), 150-153. doi:10. 1038/506150a

Pfafflin, S. M. (1974). The total time hypothesis, recall strategies, and memory for rapidly presented word strings. Memory \& Cognition, 2, 236-240. doi:10.3758/ BF03208989

Poitras, M., Pélèja, L., Lavertu, G., Langlois, A., Boulerice, K., Berthelot, P., \& ... Winder, M. (2020). A replication of waugh and norman primary memory study (1965).
The Quantitative Methods for Psychology, 16(2), 1-7. doi:10.20982/tqmp.16.2.r001

Sadeh, T., Ozubko, J. D., Winocur, G., \& Moscovitch, M. (2014). How we forget may depend on how we remember. Trends in Cognitive Sciences, 18(1), 26-36. doi:10.1016/j.tics.2013.10.008

Sadeh, T., Ozubko, J. D., Winocur, G., \& Moscovitch, M. (2016). Forgetting patterns differentiate between two forms of memory representation. Psychological Science, 27(6), 810-820. doi:10.1177/0956797616638307

Sperling, G. (1963). A model for visual memory tasks. Human factors, 5(1), 19-31. doi:10 . 1177 / 001872086300500103

Tulving, E., \& Gold, C. (1963). Stimulus information and contextual information as determinants of tachistoscopic recognition of words. Journal of Experimental Psychology, 66(4), 319-327. doi:10.1037/h0048802

Tulving, E., Mandler, G., \& Baumal, R. (1964). Interaction of two sources of information in tachistoscopic word recognition. Canadian Journal of Psychology, 18(1), 62-71. doi:10.1037/h0083296

von Hippel, W., \& Hawkins, C. (1994). Stimulus exposure time and perceptual memory. Perception \& Psychophysics, 56(5), 525-535. doi:10.3758/bf03206949

\section{Open practices}

- The Open Material badge was earned because supplementary material(s) are available on osf.io/yxz9s/.

\section{Citation}

Bradley-Garcia, M., Doucet, V., Corbeil, S., Pétrin, R., Roy, N.-L., DeNicolais, E., ... Sekeres, M. J. (2021). The influence of exposure duration and context length on word recall: A replication of Tulving et al. (1964). The Quantitative Methods for Psychology, 17(2), r1-r9. doi:10.20982/tqmp.17.2.r001

Copyright (C) 2021, Bradley-Garcia et al. This is an open-access article distributed under the terms of the Creative Commons Attribution License (CC BY). The use, distribution or reproduction in other forums is permitted, provided the original author(s) or licensor are credited and that the original publication in this journal is cited, in accordance with accepted academic practice. No use, distribution or reproduction is permitted which does not comply with these terms.

Received: 21/05/2016 Accepted: 17/06/2021

Tables 1 and 2 follow. 
Table 1 - Demographic questions asked to participants following the consent form

\begin{tabular}{|c|c|c|}
\hline Questions & Response Options & Responses \\
\hline \multirow{2}{*}{ 1. What is your sex? } & Male & $\mathrm{n}=19$ \\
\hline & Female & $\mathrm{n}=39$ \\
\hline \multirow{2}{*}{ 2. How old are you? } & I am & $18-69$ years \\
\hline & I prefer not to answer & $\mathrm{n}=1$ \\
\hline \multirow{5}{*}{$\begin{array}{l}\text { 3. Are you currently in post-secondary studies? If yes, } \\
\text { please specify }\end{array}$} & College & $\mathrm{n}=6$ \\
\hline & University - Bachelor & $\mathrm{n}=23$ \\
\hline & University - Master & $\mathrm{n}=3$ \\
\hline & University - Ph. D. & $\mathrm{n}=2$ \\
\hline & I prefer not to answer & $\mathrm{n}=24$ \\
\hline \multirow{5}{*}{ 4. What is your highest level of completed education? } & High school & $\mathrm{n}=20$ \\
\hline & College & $\mathrm{n}=17$ \\
\hline & University - Bachelor & $\mathrm{n}=12$ \\
\hline & University - Master & $\mathrm{n}=7$ \\
\hline & University - Ph. D. & $\mathrm{n}=2$ \\
\hline \multirow{4}{*}{ 5. What is your native language? } & English & $\mathrm{n}=21$ \\
\hline & French & $\mathrm{n}=33$ \\
\hline & Other & $\mathrm{n}=3$ \\
\hline & I prefer not to answer & $\mathrm{n}=1$ \\
\hline \multirow{3}{*}{ 6. What is your level of proficiency in English? } & Fluent & $\mathrm{n}=55$ \\
\hline & Moderate & $\mathrm{n}=3$ \\
\hline & Beginner & $\mathrm{n}=0$ \\
\hline \multirow{2}{*}{$\begin{array}{l}\text { 7.This experiment may present items at a fast rate. Do } \\
\text { you have a concussion or photosensitive epilepsy? }\end{array}$} & Yes & $\mathrm{n}=0$ \\
\hline & No & $\mathrm{n}=58$ \\
\hline \multirow{3}{*}{$\begin{array}{l}\text { 8. Do you have a medical or psychological condition } \\
\text { that could impact your results in an experiment on } \\
\text { short-term memory? }\end{array}$} & Yes & $\mathrm{n}=5$ \\
\hline & No & $\mathrm{n}=51$ \\
\hline & I prefer not to answer & $\mathrm{n}=2$ \\
\hline \multirow{2}{*}{$\begin{array}{l}\text { 9. In the past } 24 \text { hours, have you consumed non- } \\
\text { prescription drugs or alcohol? }\end{array}$} & Yes & $\mathrm{n}=8$ \\
\hline & No & $\mathrm{n}=50$ \\
\hline \multirow{6}{*}{ 10. How many hours of sleep did you get last night? } & 1-2 hours & $\mathrm{n}=0$ \\
\hline & 3-4 hours & $\mathrm{n}=0$ \\
\hline & 5-6 hours & $\mathrm{n}=15$ \\
\hline & 7-8 hours & $\mathrm{n}=33$ \\
\hline & 9-10 hours & $\mathrm{n}=9$ \\
\hline & More than 10 hours & $\mathrm{n}=1$ \\
\hline
\end{tabular}

Note. Participants had the option to select "I prefer not to answer," for all questions. If the response "I prefer not to answer" was not selected by at least one participant for that specific question, this answer choice was omitted from the present table. 
Table 2 a The 18 sentences with their corresponding target word, the latter being the last word of each sentence

\begin{tabular}{ll}
\hline Sentences & Target Words \\
\hline Countries in the United Nations form a military alliance & alliance \\
The political leader was challenged by a dangerous opponent & opponent \\
A voter in municipal elections must be a local resident & resident \\
The huge slum was filled with dirt and disorder & disorder \\
The ten Canadian provinces united to form a dominion & dominion \\
The light bulb was discovered by an American inventor & inventor \\
June sixth was the date of the allied invasion & invasion \\
The talented young violinist eventually became a professional musician & musician \\
Occupationally his lack of education was a serious obstacle & obstacle \\
He was sentenced to hang as a convicted murderer & murderer \\
A deadly type of bomb is made of hydrogen & hydrogen \\
Her closest relative was appointed as her legal guardian & guardian \\
The hermit retired to a place of lonely solitude & solitude \\
Many ethnic groups were represented at the folk festival & festival \\
Honesty and courage are qualities which merit wholehearted approval & approval \\
The first of the seven deadly sins is jealousy & jealousy \\
Baseball games are covered by the newspaper's sports reporter & reporter \\
He built his new house in a desirable location & location \\
\hline
\end{tabular}

